\title{
Carbohydrate composition of mucus from scleractinian corals from the central Red Sea
}

\author{
G. Hadaidi ${ }^{1}$ - H. M. Gegner ${ }^{1}$ M. Ziegler ${ }^{1,2}$ C. R. Voolstra ${ }^{1}$
}

Received: 11 September 2018/Accepted: 19 December 2018/Published online: 31 December 2018

(C) The Author(s) 2018

\begin{abstract}
Coral mucus is continuously released by most corals and acts as an important protective barrier and as a substrate for host-associated microbial communities due to its complex composition of carbohydrates, lipids, and proteins. On a reef scale, coral mucus functions as a particle trap, thereby retaining nutrients and energy in the ecosystem. Given the distinct environmental conditions in the Red Sea (high temperature, high salinity, high total alkalinity), we sought to investigate the carbohydrate composition of mucus from five corals from the central Red Sea. Our aim was to assess whether mucus from Red Sea corals is different from what is known from other corals and whether those differences could be aligned to putative beneficial functions with regard to the prevailing environment. Using gas chromatography/mass spectrometry, we detected nine sugars as the main prevalent carbohydrates. Although we detected significant differences between species with regard to the relative abundance of given carbohydrates, the identified sugars resembled those found in mucus from corals elsewhere, and we could
\end{abstract}

Topic Editor Morgan S. Pratchett

Electronic supplementary material The online version of this article (https://doi.org/10.1007/s00338-018-01758-5) contains supplementary material, which is available to authorized users.

C. R. Voolstra

christian.voolstra@kaust.edu.sa

1 Red Sea Research Center, Division of Biological and Environmental Science and Engineering (BESE), King Abdullah University of Science and Technology (KAUST), Thuwal, Saudi Arabia

2 Department of Animal Ecology and Systematics, Justus Liebig University Giessen, Heinrich-Buff-Ring 26-32, 35392 Giessen, Germany corroborate high abundance of arabinose in acroporid corals. Taken together, our results suggest the presence of a common set of carbohydrates across a broad range of coral species from geographically diverse environments, highlighting the important role of mucus with regard to coral and reef ecosystem function.

Keywords Coral reef - Mucus - Monosaccharides · Sugars $\cdot$ GC-MS $\cdot$ Metabolite

\section{Introduction}

Coral mucus is a gel-forming layer that is constantly released to varying extents and dynamically regulated by all coral species (Brown and Bythell 2005; Bythell and Wild 2011). When released, a large fraction of the mucus dissolves, leading to the formation of marine snow (Markus et al. 2006). Conversely, the non-dissolving gel-like fraction of the mucus accumulates suspended particles from the water and forms in temporal sequence mucus strings, flocs, surface films, surface layers, and mucus floats (Markus et al. 2006). Coral mucus is acting as a food source for bacteria due to its nutrient-rich components (Ducklow Hugh and Mitchell 1979; Moriarty et al. 1985; Vacelet and Thomassin 1991). At a larger scale, coral mucus plays a major role in the planktonic food chain by providing light energy harvested by the Symbiodiniaceae (LaJeunesse et al. 2018) and trapped particles to the heterotrophic reef community, thereby reducing loss of energy and nutrients from reef ecosystems (Wild et al. 2004a, 2010; Bythell and Wild 2011).

Besides the importance of coral mucus in coral reef ecosystem functioning, it also plays a fundamental role in the resilience of corals against environmental stressors 
(Brown and Bythell 2005; Ritchie 2006), e.g., through protection from pathogens (Brown and Bythell 2005; Shnit-Orland and Kushmaro 2009; Glasl et al. 2016). Notably, coral mucus serves as a habitat for bacteria that release antibiotics and other metabolites, which affect coral physiology (Koh 1997; Castillo et al. 2001; Ritchie 2006; Rosenberg et al. 2007). As such, coral mucus might mediate functions related to coral health, immunity, and resilience (Rosenberg et al. 2007; Glasl et al. 2016). More recently, Ochsenkühn et al. (2018) showed that the diffusion of mucus into the water column produces a holosphere around the coral colony that structures the coral microbiota and can be an indicator for coral health. Furthermore, it has been shown that functions related to carbohydrate metabolism are enriched in bacterial communities from corals resilient to warm environments (Ziegler et al. 2017a). Accordingly, differences in the composition of mucus from different corals may contribute to differences in their ability to respond to environmental stressors (Rohwer and Kelley 2004; Lee et al. 2016; Hadaidi et al. 2017).

The composition of coral mucus is derived from photosynthates produced by the algal symbionts and compounds acquired through heterotrophic feeding (Davies 1984; Coffroth 1990; Brown and Bythell 2005). While coral mucus consists mainly of carbohydrates (Brown and Bythell 2005), it also contains complex mixtures of glycoproteins (mucins), polysaccharides, and lipids (Coffroth 1990; Brown and Bythell 2005) that are secreted by mucocytes in the ectodermal layer (Brown and Bythell 2005). The formation of coral mucus is affected by various factors such as aerial exposure, temperature, light intensity, UV irradiation, sedimentation load, or Symbiodiniaceae type (Drollet et al. 1997; Wild et al. 2004b, 2010; Littman et al. 2009; Bessell-Browne et al. 2017). A number of studies have looked into the compositional differences of carbohydrates from coral mucus and found that although mucus production and composition vary across and within species, similar sets of carbohydrates are found (Meikle et al. 1988; Coffroth 1990; Vacelet and Thomassin 1991; Brown and Bythell 2005; Wild et al. 2005, 2010).

The Red Sea is a particularly saline and warm environment, harboring corals that are adapted to live under these extreme conditions, but the precise underlying mechanisms remain to be elucidated (Fine et al. 2013; Bellworthy and Fine 2017; Krueger et al. 2017; Ochsenkühn et al. 2017; Eslam et al. 2017). Given the importance of coral mucus to the resilience of corals and as a contributor to trophic pathways in coral reefs, we sought to provide a first account of the carbohydrate composition of mucus from a range of Red Sea corals. Our aim was to assess whether mucus from Red Sea corals is different from what is known from other corals and whether such differences could be aligned to putative beneficial functions with regard to the prevailing environment. To do this, we analyzed mucus from five coral species (Acropora pharaonis, Galaxea fascicularis, Pocillopora verrucosa, Porites lobata, and Stylophora pistillata) using gas chromatography/mass spectrometry (GC/MS) and compared our findings with studies from other regions. Our results suggest that although mucus differs between species with regard to the relative abundance of carbohydrates, overall carbohydrate mucus composition seems conserved. The conservation of mucus composition across a broad range of species and large geographic scales highlights its important role for corals globally.

\section{Materials and methods}

\section{Collection of coral mucus and environmental settings}

For this study, mucus was collected from a range of corals representing different evolutionary histories and environmental sensitivities (Voolstra et al. 2015, 2017). Mucus was sampled from coral genera from the complex (Acropora, Galaxea, Porites) and robust (Pocillopora, Stylophora) clades that also represent environmentally sensitive (Acropora, Pocillopora) and resilient (Porites, Stylophora) coral species. The genera Acropora, Pocillopora, and Porites are also considered major reef builders in the Red Sea and belong to the most abundant genera in coral reefs in the central Red Sea (Roik et al. 2016a, b, 2018). Coral mucus was collected from five coral species (three replicates: Acropora pharaonis, Galaxea fascicularis, Pocillopora verrucosa, Porites lobata, and Stylophora pistillata) from the Red Sea, Shaab reef $\left(22^{\circ} 12.038 \mathrm{~N}, 38^{\circ} 59.993 \mathrm{E}\right)$. Environmental conditions of the nearby $\left(<5 \mathrm{~km}\right.$ distance) Inner Fsar reef $\left(22^{\circ} 13.974 \mathrm{~N}\right.$, $\left.39^{\circ} 01.760 \mathrm{E}\right)$ are as follows: temperature range between $24.09{ }^{\circ} \mathrm{C}$ (winter) and $33.06{ }^{\circ} \mathrm{C}$ (summer), salinity range between 38.89 PSU (winter) and 39.87 PSU (fall), dissolved oxygen range between $0.09 \mathrm{mg} \mathrm{L}^{-1}$ (summer) and $6.11 \mathrm{mg} \mathrm{L}^{-1}$ (fall), and mean sedimentation rates between 72.88 (spring) and 192.89 (winter) $\mathrm{mg} \mathrm{m}^{-2} \mathrm{~d}^{-1}$ (Roik et al. 2016b, 2018). In August 2016 (summer), mucus samples were collected from the surface of the colonies at $4-4.5 \mathrm{~m}$ depth using sterile syringes by tapping the coral surface and collecting of mucus. Mucus samples were taken from the central surface of each colony to avoid intra-colony sampling bias. On the boat, the syringes were stored inverted on ice for ca. 20 min until the mucus had settled. Then, the supernatant seawater was ejected and the mucus was transferred into cryotubes and immediately frozen in liquid nitrogen. After snap freezing, samples were stored at $-80{ }^{\circ} \mathrm{C}$. 


\section{Coral mucus carbohydrate composition analysis}

Samples were sent to the Center of Complex Carbohydrate Research of the University of Georgia in Athens, Georgia, USA, for sample preparation and analysis (https://www. ccrc.uga.edu/services/index.php). For each sample, one milliliter of coral mucus was purified and desalted using dialysis tubing with a molecular cutoff of $50 \mathrm{kDa}$ to remove any smaller molecular weight contaminants, such as excessive amounts of salt, for glycosyl composition analyses. The cleaned-up sample material was then used in its entirety for composition analyses due to low yields of actual sample material after dialysis. In order to better compare the samples with each other, the used sample material for each sample was assumed being $\sim 100 \mu \mathrm{g}$. The sample was transferred, and its container washed 3 times with the same volume of DI water and transferred as well. Samples were dialyzed for $96 \mathrm{~h}$ and freeze-dried subsequently, before being used for composition analyses. Glycosyl composition analysis was performed by combined gas chromatography/mass spectrometry (GC/MS) of the per-O-trimethylsilyl (TMS) derivatives of the monosaccharide methyl glycosides produced from the sample by acidic methanolysis as described previously by Santander et al. (2013). Briefly, the sample $(\sim 100 \mu \mathrm{g})$ with inositol (internal standard, $20 \mu \mathrm{g}$ ) was heated with methanolic $\mathrm{HCl}$ in a sealed screw-top glass test tube for $18 \mathrm{~h}$ at $80^{\circ} \mathrm{C}$. After cooling and removal of the solvent under a stream of nitrogen, the samples were treated with a mixture of methanol, pyridine, and acetic anhydride for $30 \mathrm{~min}$. The solvents were evaporated, and the samples were derivatized with Tri-Sil ${ }^{\circledR}$ (Pierce) at $80{ }^{\circ} \mathrm{C}$ for $30 \mathrm{~min}$. GC/MS analysis of the TMS methyl glycosides was performed on an Agilent 7890A GC interfaced to a 5975C MSD, using an Supelco Equity-1 fused silica capillary column $(30 \mathrm{~m} \times 0.25 \mathrm{~mm}$ ID). Supplementary Figure S1 shows the total ion chromatogram of sample E30 representative for all samples. Supplementary Tables S1S5 provide the results of the composition analyses for all samples. The major carbohydrate residues detected in all samples were galactose, mannose, and glucose in varying quantities followed by smaller amounts of arabinose, fucose, ribose, rhamnose, xylose, and $\mathrm{N}$-acetyl glucosamine. Furthermore, we detected C16:0 and C18:0 in almost every sample, two saturated fatty acids.

\section{Data analysis}

All analyses were performed based on mole percent of total carbohydrate values (Tables S1-S5). Distribution differences were assessed with MetaboAnalyst 4.0 (Chong et al. 2018). Data were normalized by sum and auto-scaled for heatmap generation, in order to visualize data and show clustering of mucus carbohydrates. Permutational multivariate analysis of variance (PERMANOVA) was used to test for significant differences between mucus carbohydrate profiles across all coral species and between pairwise species combinations using PRIMER v6 (Clarke and Gorley 2006). To test for the differential abundance of distinct carbohydrates, data were checked for normality and homogeneity of variances with Shapiro-Wilk test and Levene test, respectively. Since the data were not normally distributed, nonparametric Kruskal-Wallis tests were conducted for each carbohydrate using R (v3.3.3) (RStudio Team 2015).

\section{Results and discussion}

In this study, we analyzed the carbohydrate composition of mucus from five coral species (Acropora pharaonis, Galaxea fascicularis, Pocillopora verrucosa, Porites lobata, and Stylophora pistillata) of the central Red Sea (Figure S1, Table S1, Table S2, Table S3, Table S4, and Table S5). Overall, we identified nine sugars, although we cannot exclude the presence of other sugars, due to the removal of compounds $<50 \mathrm{kDa}$ as a part of the dialysis process (see Material and methods). The sugars mannose, glucose, galactose, and xylose were present in all species (sorted by their relative abundance across samples). We also detected arabinose, fucose, the amino sugar $\mathrm{N}$-acetyl glucosamine, rhamnose, and ribose, but only in some species (Table 1). A. pharaonis and P. lobata were the coral species with the most diverse set of carbohydrates in this analysis. Notably, we found high variation between replicates of a given species as denoted by the high standard deviation (Table 1). In addition, the within-species replication is comparatively small $(n=3)$. For the purpose of this study, we aimed at a greater species representation at the cost of within-species replication. Future studies should incorporate a more comprehensive within-species replication and possibly also integrate within-coral replication to assess whether coral mucus composition is similar across the colony surface.

We found significant differences between coral species with regard to their mucus carbohydrate composition $\left(P_{\text {PERMANOVA }}<0.05\right)$. Subsequent pairwise comparisons showed that the following species pairs were significantly different from each other (all $P_{\text {PERMANOva }}<0.05$ ): $A$. pharaonis was significantly different from all other tested species with the exception of $P$. verrucosa, and $P$. lobata was significantly different from all other species. Thus, $A$. pharaonis and $P$. lobata were the most distinct with regard to their mucus carbohydrate composition. Species-specific differences were related to significantly different abundances in the following sugars: arabinose, fucose, 
Table 1 Carbohydrate composition of coral mucus from a range of coral species from the Red Sea ( $n=3$ for each species)

\begin{tabular}{|c|c|c|c|c|c|c|c|c|c|c|c|}
\hline \multirow[t]{2}{*}{ Carbohydrate } & \multirow[t]{2}{*}{ Chemical formula; relevance } & \multicolumn{2}{|c|}{$\begin{array}{l}\text { Acropora } \\
\text { pharaonis }\end{array}$} & \multicolumn{2}{|c|}{$\begin{array}{l}\text { Galaxea } \\
\text { fascicularis }\end{array}$} & \multicolumn{2}{|c|}{$\begin{array}{l}\text { Pocillopora } \\
\text { verrucosa }\end{array}$} & \multicolumn{2}{|c|}{$\begin{array}{l}\text { Porites } \\
\text { lobata }\end{array}$} & \multicolumn{2}{|c|}{$\begin{array}{l}\text { Stylophora } \\
\text { pistillata }\end{array}$} \\
\hline & & Mean & SD & Mean & SD & Mean & SD & Mean & SD & Mean & SD \\
\hline Arabinose & $\begin{array}{l}\mathrm{C}_{5} \mathrm{H}_{10} \mathrm{O}_{5} \text {; utilized by cyanobacteria, prevalent } \\
\text { in Acropora }\end{array}$ & 38.53 & 22.51 & n.d. & & n.d. & & 18.47 & 13.88 & n.d. & \\
\hline Fucose & $\begin{array}{l}\mathrm{C}_{6} \mathrm{H}_{12} \mathrm{O}_{5} \text {; upregulated at high temperatures, } \\
\text { prevalent in Fungia }\end{array}$ & 1.27 & 1.21 & 5.57 & 4.82 & n.d. & & 11.23 & 8.80 & n.d. & \\
\hline Galactose & $\mathrm{C}_{6} \mathrm{H}_{12} \mathrm{O}_{6}$; broadly present in coral mucus & 4.10 & 3.58 & 25.07 & 11.20 & 4.90 & & 46.97 & 15.54 & 1.80 & \\
\hline Glucose & $\begin{array}{l}\mathrm{C}_{6} \mathrm{H}_{12} \mathrm{O}_{6} \text {; common constituent of coral mucus } \\
\text { under ambient conditions }\end{array}$ & 25.10 & 10.72 & 18.33 & 6.82 & 33.63 & 13.38 & 10.07 & 3.01 & 34.93 & 8.78 \\
\hline Mannose & $\mathrm{C}_{6} \mathrm{H}_{12} \mathrm{O}_{6}$; common constituent of coral mucus & 22.30 & 12.30 & 35.13 & 15.47 & 45.47 & 7.80 & 7.27 & 3.76 & 49.00 & 1.45 \\
\hline $\begin{array}{l}\text { N-Acetyl } \\
\text { Glucosamine }\end{array}$ & $\begin{array}{l}\mathrm{C}_{8} \mathrm{H}_{15} \mathrm{NO}_{6} \text {; common constituent of coral } \\
\text { mucus, downregulated at high temperatures }\end{array}$ & 1.83 & 1.59 & 1.57 & 1.78 & n.d. & & 4.87 & 0.67 & 4.40 & \\
\hline Rhamnose & $\mathrm{C}_{6} \mathrm{H}_{12} \mathrm{O}_{5}$; common constituent of coral mucus & 1.20 & & n.d. & & n.d. & & 0.60 & & n.d. & \\
\hline Ribose & $\begin{array}{l}\mathrm{C}_{5} \mathrm{H}_{10} \mathrm{O}_{5} \text {; bacterial ribose transport } \\
\text { upregulated under heat stress }\end{array}$ & 2.10 & & n.d. & & n.d. & & 0.30 & & n.d. & \\
\hline Xylose & $\begin{array}{l}\mathrm{C}_{5} \mathrm{H}_{10} \mathrm{O}_{5} ; \text { utilized by cyanobacteria, common } \\
\text { constituent of coral mucus }\end{array}$ & 5.77 & 6.19 & 14.33 & 7.25 & 19.27 & 9.27 & 0.83 & 0.58 & 14.00 & 8.70 \\
\hline
\end{tabular}

Values are provided as means and standard deviations (SD). Values are expressed as mole percent of total carbohydrate. Cases for which we could not measure a given carbohydrate are denoted by n.d. (not detected) to avoid confounding calculations of mean and SD. No SD is provided in cases where a carbohydrate was only found in one replicate. The total mole percentage may not add to exactly $100 \%$ due to rounding

galactose, glucose, mannose, xylose, and $\mathrm{N}$-acetyl glucosamine (all $P_{\text {Kruskal-Wallis }}<0.05$ ). Notably, many of these sugars represent common constituents of coral mucus, and we could confirm trends from previous studies with regard to the prevalence of given sugars (Table 1). For instance, arabinose was previously identified as a common sugar of coral mucus and to be highly abundant in Acropora corals (Wild et al. 2010; Lee et al. 2016).

Clustering of coral species by their carbohydrate composition illustrated that arabinose, rhamnose, and ribose were particularly abundant in the mucus of A. pharaonis, and fucose, galactose, and $\mathrm{N}$-acetyl glucosamine were particularly abundant in P. lobata in comparison with the other coral species (Fig. 1). In contrast, glucose, mannose, and xylose were more prevalent in $G$. fascicularis, $P$. verrucosa, and $S$. pistillata. Notably, the pocilloporid species $P$. verrucosa and $S$. pistillata were most similar with regard to their mucus carbohydrate composition, suggesting that host phylogeny might contribute to mucus differences, possibly due to similarities in their associated microbiome (Neave et al. 2016) or Symbiodiniaceae community composition (Ziegler et al. 2017b; LaJeunesse et al. 2018). Our findings corroborate a study by Wild et al. (2010) where arabinose was present in high concentrations in mucus released from acroporid corals. Further, Meikle et al. (1988) found that arabinose is present in high concentrations in Acropora formosa and suggested that it might be transferred from the algal symbiont to the coral host, since arabinose is not a common metabolite of animal cells. Interestingly, fucose and rhamnose have low bacterial degradability and a function in coral mucus seems thus far unassigned (Amon et al. 2001; Ogawa et al. 2001; Wild et al. 2010). It will be interesting to explore the function of mucus carbohydrates that cannot be accessed by mucusassociated bacteria.

At large, arabinose, fucose, galactose, glucose, mannose, $\mathrm{N}$-acetyl glucosamine, and xylose seem common constituents of coral mucus, as they have been reported from coral species (Acropora muricata, Fungia fungites, Pachyseris speciosa, Pocillopora sp., and Stylophora sp.) across a large geographic range of regions (Aqaba, Jordan; Heron Island, Australia; Kenting National Park, Taiwan). We also found these sugars rather consistently present across corals from the Red Sea assessed here. This argues for a common set of carbohydrates in coral mucus that is conserved across species and across geographic regions. At the same time, relative abundances of these sugars seem to differ between coral species, as indicated by the significant differences between coral species found here and in other studies (Richards et al. 1983; Meikle et al. 1988; Wild et al. 2005, 2010; Lee et al. 2016). A further aspect to consider is that shifts in the concentration of some mucus components may occur under changing environmental conditions (Lee et al. 2016; Hadaidi et al. 2017). For instance, differences in mucus composition have been linked to factors such as depth, irradiance, aging, and temperature (Ducklow Hugh 


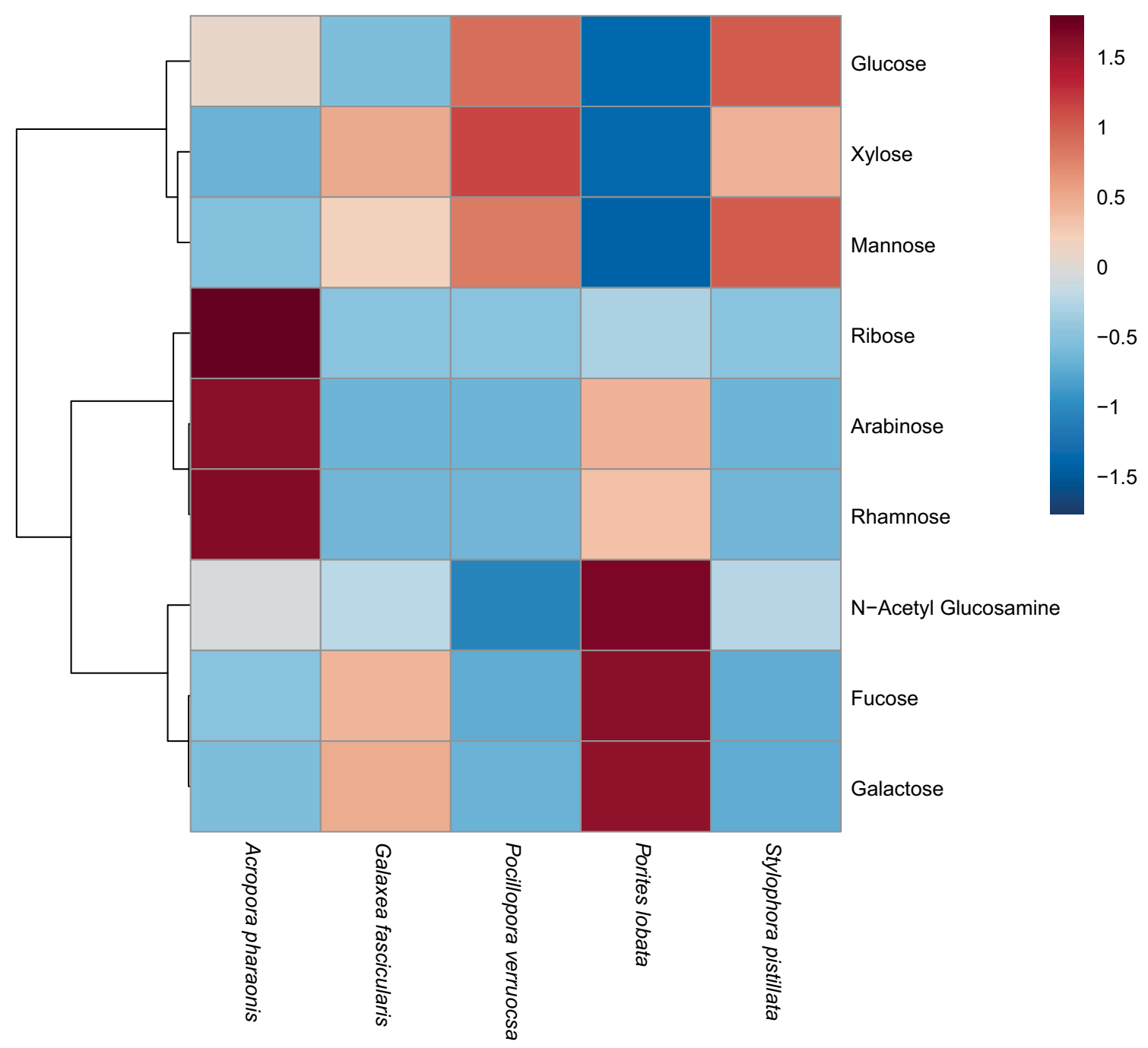

Fig. 1 Heatmap based on carbohydrate composition and abundance of mucus from five coral species of the Red Sea. Differences are displayed relative to the mean abundance for each carbohydrate over

and Mitchell 1979; Crossland et al. 1980; Daumas et al. 1981; Crossland 1987; Coffroth 1990; Wild et al. 2004a; b; Brown and Bythell 2005; Lee et al. 2016). Due to the parallel collection from the same reef site and depth in this study, we could not assess the role of environmental differences. Future studies, however, should incorporate repeated sampling across seasons to see how mucus composition changes under different environmental settings (e.g., temperature and salinity).

Taken together, in this study we found that coral mucus consists of a set of carbohydrates that seems conserved across coral species and geographic regions, although the relative abundance of sugars may differ between species (e.g., arabinose highly abundant in Acropora pharaonis, galactose in Porites lobata). As such, coral species in the Red Sea do not exhibit distinct mucus profiles with regard to the extreme conditions of the Red Sea. Rather, our study samples and species; blue denotes lower relative abundance, and red denotes higher relative abundance

highlights the consistency of mucus carbohydrates across a broad range of species and large geographic scales, suggesting an important and conserved role of mucus for corals and reef ecosystems globally.

Acknowledgement This study was funded by the King Abdullah University of Science and Technology (KAUST) under FCC/1/197322-01. This work was supported by the Chemical Sciences, Geosciences and Biosciences Division, Office of Basic Energy Sciences, U.S. Department of Energy grant (DE-SC0015662) to Parastoo Azadi at the Complex Carbohydrate Research Center. We would further like to thank the editor and two anonymous reviewers whose comments contributed greatly to the quality of the manuscript.

Author contributions MZ and CRV conceived and designed the experiments; GH, HMG, MZ, and CRV generated and analyzed the data; MZ, HMG, and CRV provided reagents/materials/tools; CRV, $\mathrm{MZ}$, and $\mathrm{GH}$ wrote the manuscript. 


\section{Compliance with ethical standards}

Conflict of interest The authors hereby declare that no conflict of interest exists.

Open Access This article is distributed under the terms of the Creative Commons Attribution 4.0 International License (http://crea tivecommons.org/licenses/by/4.0/), which permits unrestricted use, distribution, and reproduction in any medium, provided you give appropriate credit to the original author(s) and the source, provide a link to the Creative Commons license, and indicate if changes were made.

\section{References}

Amon R, Fitznar H, Benner R (2001) Linkages among the bioreactivity, chemical composition, and diagenetic state of marine dissolved organic matter. Limnology and Oceanography 46:287-297

Bellworthy J, Fine M (2017) Beyond peak summer temperatures, branching corals in the Gulf of Aqaba are resilient to thermal stress but sensitive to high light. Coral Reefs 36:1071-1082

Bessell-Browne P, Fisher R, Duckworth A, Jones R (2017) Mucous sheet production in Porites: an effective bioindicator of sediment related pressures. Ecological Indicators 77:276-285

Brown B, Bythell J (2005) Perspectives on mucus secretion in reef corals. Marine Ecology Progress Series 296:291-309

Bythell JC, Wild C (2011) Biology and ecology of coral mucus release. Journal of Experimental Marine Biology and Ecology 408:88-93

Castillo I, Lodeiros C, Núñez M, Campos I (2001) In vitro evaluation of antibacterial substances produced by bacteria isolated from different marine organisms. Rev Biol Trop 49:1213-1222

Chong J, Soufan O, Li C, Caraus I, Li S, Bourque G, Wishart DS, Xia J (2018) MetaboAnalyst 4.0: towards more transparent and integrative metabolomics analysis. Nucleic Acids Research:gky310-gky310

Clarke K, Gorley R (2006) PRIMER V6: user Manual/Tutorial. Primer-E Ltd, Ivybridge

Coffroth MA (1990) Mucous sheet formation on poritid corals: An evaluation of coral mucus as a nutrient source on reefs. Marine Biology 105:39-49

Crossland CJ (1987) In situ release of mucus and DOC-lipid from the corals Acropora variabilis and Stylophora pistillata in different light regimes. Coral Reefs 6:35-42

Crossland CJ, Barnes DJ, Borowitzka MA (1980) Diurnal lipid and mucus production in the staghorn coral Acropora acuminata. Marine Biology 60:81-90

Daumas R, Galois R, Thomassin BA (1981) Biochemical composition of soft and hard coral mucus on a New Caledonian lagoonal reef. Proceedings of the 4th International Coral Reef Symposium:5967

Davies PS (1984) The role of zooxanthellae in the nutritional energy requirements of Pocillopora eydouxi. Coral Reefs 2:181-186

Drollet JH, Teai T, Faucon M, Martin PMV (1997) Field study of compensatory changes in UV-absorbing compounds in the mucus of the solitary coral Fungia repanda (Scleractinia: Fungiidae) in relation to solar UV radiation, sea-water temperature, and other coincident physico-chemical parameters. Marine and Freshwater Research 48:329-333

Ducklow Hugh W, Mitchell R (1979) Bacterial populations and adaptations in the mucus layers on living corals1. Limnology and Oceanography 24:715-725
Fine M, Gildor H, Genin A (2013) A coral reef refuge in the Red Sea. Global Change Biology 19:3640-3647

Glasl B, Herndl GJ, Frade PR (2016) The microbiome of coral surface mucus has a key role in mediating holobiont health and survival upon disturbance. ISME J

Hadaidi G, Röthig T, Yum LK, Ziegler M, Arif C, Roder C, Burt J, Voolstra CR (2017) Stable mucus-associated bacterial communities in bleached and healthy corals of Porites lobata from the Arabian Seas. Scientific Reports 7:45362

Koh EG (1997) Do scleractinian corals engage in chemical warfare against microbes? Journal of Chemical Ecology 23:379-398

Krueger T, Horwitz N, Bodin J, Giovani M-E, Escrig S, Meibom A, Fine M (2017) Common reef-building coral in the Northern Red Sea resistant to elevated temperature and acidification. Royal Society Open Science 4:170038-170038

LaJeunesse TC, Parkinson JE, Gabrielson PW, Jeong HJ, Reimer JD, Voolstra CR, Santos SR (2018) Systematic Revision of Symbiodiniaceae Highlights the Antiquity and Diversity of Coral Endosymbionts. Current Biology 28:2570-2580.e2576

Lee STM, Davy SK, Tang S-L, Kench PS (2016) Mucus Sugar Content Shapes the Bacterial Community Structure in Thermally Stressed Acropora muricata. Frontiers in Microbiology 7:371

Littman RA, Willis BL, Bourne DG (2009) Bacterial communities of juvenile corals infected with different Symbiodinium (dinoflagellate) clades. Marine Ecology Progress Series 389:45-59

Markus H, Christian W, Sabine G (2006) Mucus trap in coral reefs: formation and temporal evolution of particle aggregates caused by coral mucus. Marine Ecology Progress Series 307:69-84

Meikle P, Richards GN, Yellowlees D (1988) Structural investigations on the mucus from six species of coral. Marine Biology 99:187-193

Moriarty DJW, Pollard PC, Hunt WG (1985) Temporal and spatial variation in bacterial production in the water column over a coral reef. Marine Biology 85:285-292

Neave MJ, Rachmawati R, Xun L, Michell CT, Bourne DG, Apprill A, Voolstra CR (2016) Differential specificity between closely related corals and abundant Endozoicomonas endosymbionts across global scales. ISME J 11:186

Ochsenkühn MA, Schmitt-Kopplin P, Harir M, Amin SA (2018) Coral metabolite gradients affect microbial community structures and act as a disease cue. Communications Biology 1:184

Ochsenkühn MA, Röthig T, D'Angelo C, Wiedenmann J, Voolstra CR (2017) The role of floridoside in osmoadaptation of coralassociated algal endosymbionts to high-salinity conditions. Science Advances 3

Ogawa H, Amagai Y, Koike I, Kaiser K, Benner R (2001) Production of Refractory Dissolved Organic Matter by Bacteria. Science 292:917

Osman Eslam O, Smith David J, Ziegler M, Kürten B, Conrad C, ElHaddad Khaled M, Voolstra Christian R, Suggett David J (2017) Thermal refugia against coral bleaching throughout the northern Red Sea. Global Change Biology 24:e474-e484

Richards G, Meikle P, Yellowlees D (1983) Preliminary investigations into the chemical nature of mucus from the staghorn coral (Acropora formosa). Proc Inaug Great Barrier Reef Conf $1: 353-359$

Ritchie KB (2006) Regulation of microbial populations by coral surface mucus and mucus-associated bacteria. Marine Ecology Progress Series 322:1-14

Rohwer F, Kelley S (2004) Culture-Independent Analyses of CoralAssociated Microbes. In: Rosenberg E, Loya Y (eds) Coral Health and Disease. Springer, Berlin Heidelberg, pp 265-277

Roik A, Roder C, Röthig T, Voolstra CR (2016a) Spatial and seasonal reef calcification in corals and calcareous crusts in the central Red Sea. Coral Reefs 35:681-693 
Roik A, Röthig T, Roder C, Ziegler M, Kremb SG, Voolstra CR (2016b) Year-Long Monitoring of Physico-Chemical and Biological Variables Provide a Comparative Baseline of Coral Reef Functioning in the Central Red Sea. PLoS ONE 11:e0163939

Roik A, Röthig T, Pogoreutz C, Saderne V, Voolstra CR (2018) Coral reef carbonate budgets and ecological drivers in the central Red Sea - a naturally high temperature and high total alkalinity environment. Biogeosciences 15:6277-6296

Rosenberg E, Koren O, Reshef L, Efrony R, Zilber-Rosenberg I (2007) The role of microorganisms in coral health, disease and evolution. Nature Reviews Microbiology 5:355-362

RStudio Team (2015) RStudio: Integrated Development for R. RStudio, Inc., Boston, MA URL http://www.rstudio.com/

Santander J, Martin T, Loh A, Pohlenz C, Gatlin DM, Curtiss R (2013) Mechanisms of intrinsic resistance to antimicrobial peptides of Edwardsiella ictaluri and its influence on fish gut inflammation and virulence. Microbiology 159:1471-1486

Shnit-Orland M, Kushmaro A (2009) Coral mucus-associated bacteria: a possible first line of defense. FEMS Microbiology Ecology 67:371-380

Vacelet E, Thomassin BA (1991) Microbial utilization of coral mucus in long term in situ incubation over a coral reef. Hydrobiologia 211:19-32

Voolstra CR, Li Y, Liew YJ, Baumgarten S, Zoccola D, Flot J-F, Tambutté S, Allemand D, Aranda M (2017) Comparative analysis of the genomes of Stylophora pistillata and Acropora digitifera provides evidence for extensive differences between species of corals. Scientific Reports 7:17583
Voolstra CR, Miller DJ, Ragan MA, Hoffmann A, Hoegh-Guldberg O, Bourne D, Ball E, Ying H, Foret S, Takahashi S, Weynberg $\mathrm{KD}$, van Oppen MJ, Morrow K, Chan CX, Rosic N, Leggat W, Sprungala S, Imelfort M, Tyson GW, Kassahn K, Lundgren P, Beeden R, Ravasi T, Berumen M, Abel E, Fyffe T (2015) The ReFuGe 2020 consortium - Using 'omics' approaches to explore the adaptability and resilience of coral holobionts to environmental change. Frontiers in Marine Science 2

Wild C, Woyt H, Huettel M (2005) Influence of coral mucus on nutrient fluxes in carbonate sands. Marine Ecology Progress Series 287:87-98

Wild C, Naumann M, Niggl W, Haas A (2010) Carbohydrate composition of mucus released by scleractinian warm- and coldwater reef corals. Aquatic Biology 10:41-45

Wild C, Huettel M, Klueter A, Kremb SG, Rasheed MYM, Jørgensen BB (2004a) Coral mucus functions as an energy carrier and particle trap in the reef ecosystem. Nature 428:66

Wild C, Rasheed M, Werner U, Franke U, Johnstone R, Huettel M (2004b) Degradation and mineralization of coral mucus in reef environments. Marine Ecology Progress Series 267:159-171

Ziegler M, Seneca FO, Yum LK, Palumbi SR, Voolstra CR (2017a) Bacterial community dynamics are linked to patterns of coral heat tolerance. Nature Communications 8:14213

Ziegler M, Arif C, Burt JA, Dobretsov S, Roder C, LaJeunesse TC, Voolstra CR (2017b) Biogeography and molecular diversity of coral symbionts in the genus Symbiodinium around the Arabian Peninsula. Journal of Biogeography 44:674-686 